\title{
A Review on the Contemporary Status of Mutating Coronavirus and Comparative Literature Study of Current COVID-19 Vaccines
}

\author{
Mohammed Shadab Shahab, ${ }^{1,2}$, Syed Sarim Imam ${ }^{3}$ and Mohammed Asadullah Jahangir ${ }^{* 1}$ \\ ${ }^{1}$ Department of Pharmaceutics, Nibha Institute of Pharmaceutical Sciences, Rajgir-803116, India \\ ${ }^{2}$ Department of Pharmaceutics, Glocal School of Pharmacy, Glocal University, Saharanpur, India \\ ${ }^{3}$ Department of Pharmaceutics, College of Pharmacy, King Saud University, Riyadh, Saudi Arabia
}

Article info

Received 30 April 2021

Revised 05 June 2021

Available Online 7 June 2021

*Corresponding author: Dr. M. Asadullah Jahangir, Department of Pharmaceutics, Nibha Institute of Pharmaceutical Sciences, Rajgir803116, India

\begin{abstract}
The Novel corona virus was first reported in Wuhan province of China in the late 2019. It outspread rapidly which led to a new health crisis throughout the world by the beginning of March 2020 and was considered as a global epidemic. Several deteriorating health symptoms, morbidity and mortality were reported globally by WHO, with more than 34 lakh deaths being reported by 26 May 2021. Presently 16 vaccines are approved under emergency use in different countries and more than 33 vaccines are under phase 3 clinical trials and nearly 130 vaccines are in development phase. By the end of 2020 several new variants in U.K, South Africa, Brazil and India were reported which caused the second wave of COVID-19, for which new trials of vaccine are running to evaluate the efficacy and safety. Several technical problems are associated regarding the production, storing and supplying of these vaccines. For controlling the epidemic, the major challenge is to produce billions of vaccines and to make it available to the underdeveloped and poorer nations. This extensive review provides the details of the different variants of corona viruses reported in the different regions of the world, current vaccines approved under emergency use which are being administered throughout the globe, on-going and listed clinical trials on different vaccines under study for possible use in Covid-19 virus and future challenges associated with Covid-19 scenario.
\end{abstract}

Keywords: COVID-19 (Novel coronavirus); Receptor Binding Domain (RBD); Severe Acute Respiratory Syndrome Coronavirus 2 (SARS-COV-2); Emergency Use Authorization (EUA); World Health Organization (WHO); Vaccines; Middle East Respiratory Syndrome (MERS); COVID variants; Immunization; Vaccination; Oxford/AstraZeneca; Sputnik V; Novavax; Moderna mRNA; Covaxin; Janssen; Covac; Covishield

\section{Introduction}

Coronaviruses (CoVs) allied with substantial disease epidemics in East Asia and the Middle East which later spread to Europe. Over the past decades SARS and MERS emerges in beginning of $21^{\text {st }}$ century. Later in 2019 the emergence of novel coronavirus also called severe acute respiratory syndrome coronavirus 2
(SARS-CoV-2), causing coronavirus disease 2019 (COVID-19) pretended a global threat to mankind [1,2]. The Novel CoV (2019-nCoV), which was first identified on 12 December 2019 in Wuhan City, Hubei Province, China. Globally Health care-workers are making efforts to control the pandemic caused by the 
novel Corona virus (originally named 2019-new corona virus), belong to the family Coronaviridae (subfamily Coronavirinae), it infects a wide-range of hosts, exhibiting conditions like common to severe cold and fever, and ultimately fatal illnesses like SARS, MERS. The Corona family that causes infection in humans consists of 7 members SARS-CoV-2 is one of them [3] belonging to the same ancestry of CoVs which causes SARS having distinct genetic material. By the end of 2020, six variants of Coronaviruses were reported to infect humans which were HCoV 229E (HCoV-229E), HCoV-NL63, HCoV-OC43, HCoV-HKU1, SARS$\mathrm{CoV}$, and MERS-CoV. Among these SARS-CoV and MERS-CoV reported elevation in mortality, which were previously found to cause only upper-respiratory tract infection [4,5]. The recent outburst of Coronavirus poses global public health risk. Fan et al. predicted the potential SARS- or MERS-like Coronavirus aroused in China following the pathogen distribution from bats which blowout rapidly to other countries [6]. Currently some vaccines are approved under emergency use authorization for prophylactic use against coronaviruses. In the meantime, by the end of 2020 multiple new strain of COVID were reported in United Kingdom (U.K.), South Africa and in India in the mid2021.

\section{The Virus (SARS-CoV-2)}

According to the International Committee on Taxonomy of Viruses (ICTV), the virus associated to the severe acute respiratory syndrome-related coronavirus group are called as SARS-COV-2 [7]. They are classified as order Nidovirales, family Coronaviridae, subfamily Ortho-coronavirinae, genera classified as viz., Alpha, Beta, Gamma, and Deltacoronavirus. The origin of source of Alpha and Betacoronavirus is from bats, whereas Gamma and Deltacoronavirus have developed from birds and swine gene pools $[8,9]$. Recently few mutations have been reported in the corona virus, and is lesser than most RNA viruses, the alteration exhibited by encoding an enzyme which modifies the errors made during the replication [10]. The proofreading study yields that RNA of Corona virus-19 has identified replication. Despite the presence of a Corona virus-19 RNA proofreading activity that yields high replication conformity, reporting of D614G mutation affecting the spike glycoprotein of SARSCoV-2 strains was reported from Europe in February 2020. Since the time of reporting the new variant spread briskly which turn out to be the most widespread genotype globally [11]. In recent times D614Gassociated SARS-CoV-2 infected patients displayed abundance of virus availability on the upper airways compared to the original unmutated COVID-19 strain, however the infection related severeness was not increased. Pseudo-typed virus having G614 on the spike protein of SARS-COV-2 depicted climb in infection on the cell line study, with increased sensitivity toward neutralization. The structural analysis study disclosed that Receptor binding domain (RBD) of the G614 form of Novel coronavirus spike protein expressed an "open" conformation than the RBD of ancestral D614 $[12,13]$. In the beginning of March 2020 D614G mutation in the spikes of SARS-CoV-2 was first noticed which rapidly spread globally and dominated over the next few months. By September 2020, a new variant, referred to as SARS-CoV-2 VUI 202012/01 (Variant Under Investigation, year 2020, month 12, variant 01), has been recognized through viral genomic sequencing in the United Kingdom later defined by multiple spike protein mutations. This new variant reported in the southern Kent of England which rapidly increased to the eastern and other areas of England including London. By the mid of December new variant spread to other parts of Europe, and Southeast Asian countries [1415].

\section{Transforming SARS COVID 2 Variants}

The changes in genetic code of a virus in an infected animal or person led to exhibition of virus variants. By the end of 2020, various SARS-COVID-2 variants emerged globally depicting different mutation in virus. Some of the agencies monitoring the new strain of COV-2 variants reported fresh outbreak in countries like United Kingdom, South Africa, Brazil. The rapidly emerging Variants of SARS -COVID-2 consists of new info about the virologic, epidemiologic, and clinical features are summarized below [1316]. Table 1 tabulates the list of reported genomic properties of the new SARS-CoV-2 variant $[11,12,14,16-20]$. 
Citation: Shahab MS, Imam SS, Jahangir MA. A Review on the Contemporary Status of Mutating Coronavirus and Comparative Literature Study of Current COVID-19 Vaccines. Int J Pharm Pharmacol 2021; 5: 153. doi: 10.31531/2581-3080.1000153

Table 1: List of reported genomic properties of the new SARS-CoV-2 variant.

\begin{tabular}{|c|c|c|c|}
\hline Origin Country & SARS-COVID-2 variants & Mutation type & Mutation site \\
\hline United Kingdom & $\begin{array}{l}\text { 20I/501Y.V1, VOC 202012/01 } \\
\text { or B.1.1.7 }\end{array}$ & N501Y, P681H E484K & Spike protein \\
\hline South Africa & $20 \mathrm{H} / 501 \mathrm{Y} . \mathrm{V} 2$ or B.1.351) & $\begin{array}{l}\text { K417N, E484K and } \\
\text { N501Y }\end{array}$ & $\begin{array}{l}\text { Whole genomes and } \\
\text { spike protein }\end{array}$ \\
\hline Brazil & P.1/P2 or B.1.1.28 & $\begin{array}{l}\text { K417N/T, } \quad \text { E484K, } \\
\text { N501Y }\end{array}$ & Spike protein \\
\hline $\begin{array}{ll}\text { USA } & \text { (Southern } \\
\text { California) } & \end{array}$ & CAL.20C or B.1.427/429 & L452R mutation & Spike protein \\
\hline India & B.1.617 & $\begin{array}{l}\text { E484Q, } \quad \text { L452R and } \\
\text { P681R }\end{array}$ & Spike protein \\
\hline Uganda & A.23.1 & $\begin{array}{l}\text { F157L, V367F, Q613H } \\
\text { and P681R }\end{array}$ & Spike protein \\
\hline
\end{tabular}

\section{Current Worldwide Scenario of Novel Coronavirus}

The current outburst of Covid-19 is a Group 2B Coronavirus. The genomic sequence of SARS-CoV-2 obtained from human demonstrated $79.5 \%$ resemblance compared to SARS [12,16]. WHO reported $170,747,372$ cases of covid and 3,555,746 mortality throughout the world [21].

\section{SARS-Cov-2 Variants Genomic Properties}

The new variant of SARS-Covid-2 virus stated in the United Kingdom as SARS-CoV-2 VUI 202012/01; exhibited several genetical alteration in spike protein (deletion 69-70, deletion 144, N501Y, A570D, D614G, P681H, T716I, S982A, D1118H) existent along with mutations in supplementary genomic regions. The receptor binding domain (RBD) is the location of N501Y mutation of spike proteins [18,22].

\section{A Lookout on New Variant of SARS-Cov-2 Appearance, Transmission and Spreading}

SARS-CoV-2 virus new variant is more transmissible and has been detected globally. The Brazilian variant P.1 or VOC202101/02 in the UK, was first identified in Brazilian traveller who reached Japan in January 2021. 17 unique amino acid changes were observed in UK SARS-CoV-2 Brazilian variant having three deletions, four synonymous mutations including $\mathrm{E} 484 \mathrm{~K}$ and
N501Y. The Brazilian variant of SARS-CoV-2 (recognised as P.1) processed 17 unique mutations in which 3 of the mutation occurred in the receptor binding spike protein. Another variant of SARS-CoV-2 (known as $20 \mathrm{H} / 501$ Y.V2 or B.1.351) of South Africa mutated with United Kingdom variant B.1.1.7 shows different mutation in spike protein. B.1.1.7 lineage variant has shown a mutation in the receptor binding domain (RBD) of the spike protein and was assisting to increase the transmissibility, which was reported to have first appeared in the UK during September 2020 [13,18,20,23]. According to WHO more than 337,989 deaths and 27,369,093 confirmed cases occurred in India between 3 Jan 2020 to 3 June 2021 [24]. However, major cases arouse in $2^{\text {nd }}$ wave of pandemic occurred due to COVID-19 variants rolling over daily cases of covid infections, which leads to rise in death tolls in the month of late March to May of 2021 In the meantime, the evolution of spike mutation at L452R, E484Q and P681R in COVID 19 variants were reported in western India, identified as B.1.617 lineage, it was found to be highly spreading variant which spread globally in 21 different countries. Recently 3 subtypes of this variant have been identified as B.1.617.1, B.1.617.2, and B.1.617.3, each possess different genetic appearance. Amongst these B.1.617.1, B.1.617.2 was first reported in December 2020 and the latter was reported to be $50 \%$ more transmissible than U.K variant B.1.1.7 [19,25]. 
Recently in May 2021, Vietnam declared a hybrid variant of India's B.1.617.2 variant and U.K B.1.1.7 variant reported to be more transmissible than the previous variants. On 31 May 2021, WHO recommended a new system for naming of novel coronavirus variants which are labelled with Greek letters are listed in Table 2 [26]

Table 2: WHO recommended new system for naming of different variants of novel coronaviruses.

\begin{tabular}{|l|l|l|}
\hline Origin country of Covid 19 variants & Greek Letters (New Name) & Variant/lineage \\
\hline United Kingdom & Alpha $(\alpha)$ & B.1.1.7 \\
\hline South Africa & Beta $(\beta)$ & B.1.351 \\
\hline Brazil & Gamma $(\gamma)$ & P.1 \\
\hline India & Delta $(\delta)$ & B.1617.2 \\
\hline USA (South California) & Epsilon $(\varepsilon)$ & B.1.427/429 \\
\hline Brazil & Zeta $(\zeta)$ & P.2 \\
\hline Different countries & Eta $(\eta)$ & B.1.525 \\
\hline Philippines & Theta $(\theta)$ & P.3 \\
\hline USA (New York) & Iota $(1)$ & B.1.526 \\
\hline India & Kappa $(\kappa)$ & B.1617.1 \\
\hline
\end{tabular}

\section{The Therapy}

A number of medicines have been subjected to trials against the SAARS -COV-2, however none of them shown worthy with promising effectiveness against the infection. Meanwhile in a clinical trial (NCT04280705), a broad spectrum antiviral drug Remdesivir at a dose of $200 \mathrm{mg}$ IV on day 1 followed by $100 \mathrm{mg}$ IV once daily for next 4 days have been reported to show quicker recovery by preventing the patient's severe respiratory conditions. They act by interfering with the enzyme RNA-dependent RNA polymerase required to replicate the virus RNA, resulting in halting the multiplication of virus [27-29].

In the second wave of Covid pandemic, ICMR under Govt of India has approved the use of Remdesivir as an investigational therapy under National Clinical Management Protocol for Covid19 and Toclizumab an immunosuppressive Interleukin 6 inhibitor was also recommended at a dose of 4 to $6 \mathrm{mg} / \mathrm{kg}$ in normal saline over 1 hour [30].
On May 01, 2021, Drug Control general of India (DCGI) has permitted, the usage of an anti-Covid drug, named 2-deoxy-D-glucose (2-DG), developed in collaboration by INMAS and Dr Reddy's was reported to speed up recovery of covid-19 patients and was also found to reduce their oxygen dependence demonstrated under clinical trial (CT/ND/36/2020) phase 3 performed on 220 patients [31]. The trial report suggested that 2-deoxy-D-glucose (2-DG) can be used as an adjunct therapy to assist the primary treatment. It works by accumulating in the virus-infected cells ultimately altering the viral growth by blocking viral synthesis and energy yielding. It is dispensed in powder form and have to be dissolved in water before consumption. However, no commercial data is available as the drug has not been launched yet [32-34].

Despite all these efforts no proper medication towards the complete treatment of the SARS COVID -2 virus have been developed. Therefore, other mode of treatments is being exploited to enhance the immunogenicity against the virus. Several drug laboratories and pharmaceutical 
companies are working to explore and develop vaccines to serve the purpose.

\section{The Vaccines}

A vaccine is a suspension having attenuated live or inactivated pathogen loaded to genetically altered portions of the pathogen proteins, which triggers the production of antibodies against specific antigens and thus, protects the vaccinated person from any future exposure to that particular antigen [35]. Vaccines works by organising the body's natural resistance on distinguishing and curb off the viruses. Post-vaccination, if the individuals is later exposed to these disease causing antigens, the body is straightaway prepared to abolish them and thus, inhibits the illness [36].

To handle the pandemic scenario of covid-19 virus, different vaccines are being developed and many have been given approval for vaccination against COVID-19. A total of 1,546,316,352 vaccine doses have been administered worldwide by the last week of May 2021 [24,37]. A number of vaccine platform have been used to formulate the vaccine viz; whole vaccine and component vaccines which are enlisted below [38,39].

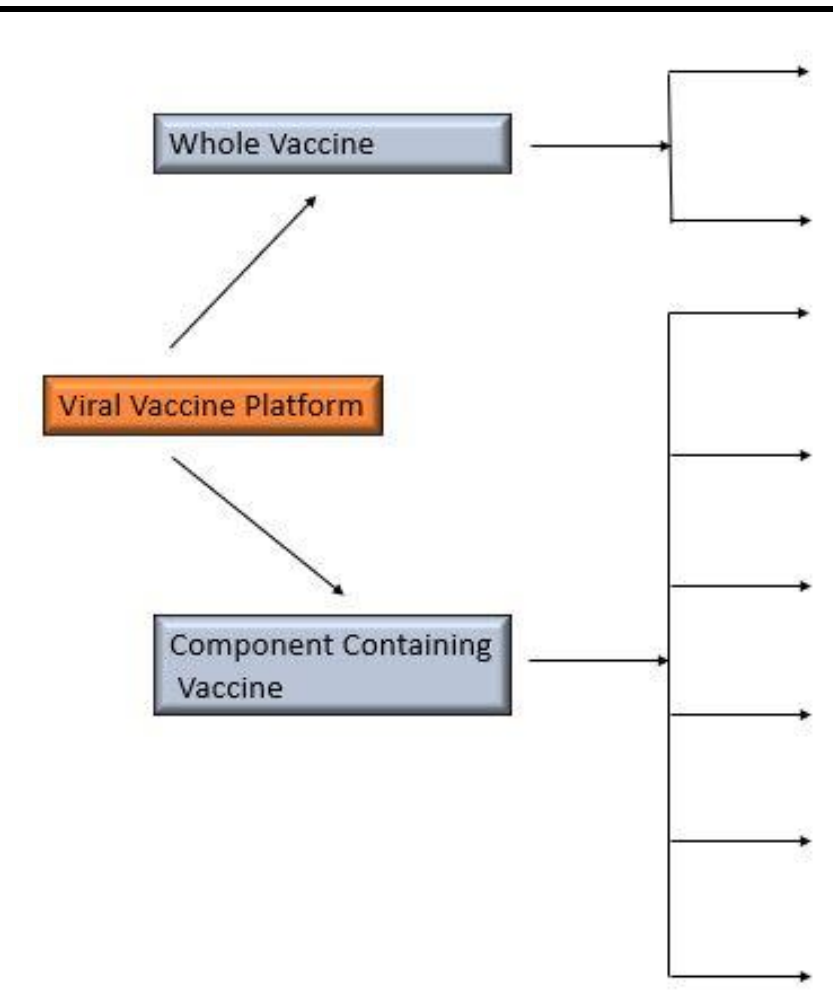

Figure 1: Different viral vaccine platforms.

By the last month of 2020, a number of COVID-19 vaccines outdid the clinical trials phases and were authorized for emergency use by the US FDA. In early December 2020, the U.S. Food and Drug Administration issued emergency use authority to Pfizer-BioNTech COVID-19 vaccine, later by the end of year, the Moderna COVID vaccine also got the permission under same emergency provision to be vaccinate in individual of 18 year or above age persons infected by SARS- COVID-2 pathogen [40]. According to WHO, by mid-February 2021, seven different vaccines across three platforms have been rolled out in several countries which have vulnerable population are on highest priority to be vaccinated. Vaccines under emergency used listing issued by WHO are Pfizer COVID-19 vaccine (BNT162b2), two versions of the AstraZeneca/Oxford COVID-19 vaccine manufactured by the Serum Institute of India and AstraZeneca - SK Bio (South Korea), Janssen Ad26.COV2.S developed by Johnson \& Johnson on. Moderna Biotech COVID 19 mRNA -1273 vaccine got WHO listing in the last week of April 2021, Sinopharm inactivated vaccine 
Citation: Shahab MS, Imam SS, Jahangir MA. A Review on the Contemporary Status of Mutating Coronavirus and Comparative Literature Study of Current COVID-19 Vaccines. Int J Pharm Pharmacol 2021; 5: 153. doi: $\underline{10.31531 / 2581-3080.1000153}$

called BBIBP-CorV got emergency use approval in the first week of May 7, 2021 [41]. However, under WHO Covax epidemic control programme of more than 7 vaccines are in portfolio including Novavax (NVXCoV2373) vaccine and Sanofi-GSK: Recombinant Protein vaccines [42].
Currently there are 16 approved vaccines to be used in SARS-COVID-2 by at least one country after clearing the clinical trial phases are enlisted below in Table 3 [43-45].

Table 3: List of vaccines, NCT number, number of trials being conducted, vaccine types, number of countries in which these vaccines are approved and their developers.

\begin{tabular}{|c|c|c|c|c|c|}
\hline Vaccine & NCT Number & $\begin{array}{l}\text { No. of } \\
\text { trials in } \\
\text { countries }\end{array}$ & $\begin{array}{l}\text { Vaccine } \\
\text { type }\end{array}$ & $\begin{array}{c}\text { No. of } \\
\text { countries } \\
\text { in which } \\
\text { vaccines } \\
\text { are } \\
\text { approved }\end{array}$ & Developers \\
\hline Epivac Corona & $\begin{array}{l}\text { NCT04527575 } \\
\text { NCT04780035 }\end{array}$ & $\begin{array}{l}3 \text { trials in } \\
1 \text { country }\end{array}$ & $\begin{array}{l}\text { Protein } \\
\text { Subunit }\end{array}$ & 2 & FBRI SRC VB VECTOR \\
\hline BNT162b2 & $\begin{array}{l}\text { NCT04368728 } \\
\text { NCT04380701 } \\
\text { NCT04649021 } \\
\text { NCT04588480 }\end{array}$ & $\begin{array}{l}19 \text { trials } \\
\text { in } 13 \\
\text { countries }\end{array}$ & RNA & 85 & BioNTech, Pfizer \\
\hline mRNA-1273 & $\begin{array}{l}\text { NCT04649151 } \\
\text { NCT04470427 } \\
\text { NCT04405076 } \\
\text { NCT04283461 }\end{array}$ & $\begin{array}{l}5 \text { trials in } \\
1 \text { country }\end{array}$ & RNA & 37 & Moderna, NIAID \\
\hline Ad5-nCoV & $\begin{array}{l}\text { NCT04313127 } \\
\text { NCT04341389 } \\
\text { NCT04568811 } \\
\text { NCT04566770 } \\
\text { NCT04540419 } \\
\text { NCT04526990 }\end{array}$ & $\begin{array}{l}8 \text { trials in } \\
6 \\
\text { countries }\end{array}$ & $\begin{array}{l}\text { Non } \\
\text { Replicating } \\
\text { viral } \\
\text { Vector }\end{array}$ & 5 & CanSino \\
\hline Sputnik V & $\begin{array}{l}\text { NCT04640233 } \\
\text { NCT04713488 } \\
\text { NCT04436471 } \\
\text { NCT04437875 } \\
\text { NCT04686773 } \\
\text { NCT04587219 } \\
\text { NCT04741061 } \\
\text { NCT04642339 } \\
\text { NCT04656613 } \\
\text { NCT04564716 } \\
\text { NCT04530396 }\end{array}$ & $\begin{array}{l}19 \\
\text { trials in } 6 \\
\text { countries }\end{array}$ & $\begin{array}{l}\text { Non } \\
\text { Replicating } \\
\text { viral vector }\end{array}$ & 68 & Gamaleya \\
\hline Ad26.COV2.S & $\begin{array}{l}\text { NCT04505722 } \\
\text { NCT04614948 } \\
\text { NCT04535453 } \\
\text { NCT04436276 } \\
\text { NCT04509947 }\end{array}$ & $\begin{array}{l}8 \text { trials in } \\
17 \\
\text { countries }\end{array}$ & $\begin{array}{l}\text { Non } \\
\text { Replicating } \\
\text { viral vector }\end{array}$ & 41 & $\begin{array}{l}\text { Janssen (Johnson \& } \\
\text { Johnson) }\end{array}$ \\
\hline
\end{tabular}


Citation: Shahab MS, Imam SS, Jahangir MA. A Review on the Contemporary Status of Mutating Coronavirus and Comparative Literature Study of Current COVID-19 Vaccines. Int J Pharm Pharmacol 2021; 5: 153. doi: $\underline{10.31531 / 2581-3080.1000153}$

\begin{tabular}{|c|c|c|c|c|c|}
\hline AZD1222 & $\begin{array}{l}\text { NCT04324606 } \\
\text { NCT04444674 } \\
\text { NCT04568031 } \\
\text { NCT04686773 } \\
\text { NCT04400838 } \\
\text { NCT04540393 } \\
\text { NCT04516746 } \\
\text { NCT04536051 }\end{array}$ & $\begin{array}{l}28 \\
\text { trials in } \\
17 \\
\text { countries }\end{array}$ & $\begin{array}{l}\text { Non } \\
\text { Replicating } \\
\text { viral vector }\end{array}$ & 101 & $\begin{array}{l}\text { Oxford / AstraZeneca or } \\
\text { Vaxzevria }\end{array}$ \\
\hline Covishield & $\begin{array}{l}\text { CTRI/2020/08/027170 } \\
\text { (Registered in ICMR) }\end{array}$ & $\begin{array}{l}2 \text { trials in } \\
1 \text { country }\end{array}$ & $\begin{array}{l}\text { Non } \\
\text { Replicating } \\
\text { viral vector }\end{array}$ & 40 & Serum Institute of India \\
\hline Covaxin & $\begin{array}{l}\text { NCT04471519 } \\
\text { NCT04641481 }\end{array}$ & $\begin{array}{l}5 \text { trials in } \\
1 \text { country }\end{array}$ & Inactivated & 9 & Bharat Biotech \\
\hline BBIBP-CorV & $\begin{array}{l}\text { NCT04560881 } \\
\text { NCT04510207 } \\
\text { NCT04612972 } \\
\text { ChiCTR2000034780 } \\
\text { ChiCTR2000032459 }\end{array}$ & $\begin{array}{l}6 \text { trials in } \\
7 \\
\text { countries }\end{array}$ & Inactivated & 42 & Sinopharm (Beijing) \\
\hline WIBP-CorV & $\begin{array}{l}\text { ChiCTR2000031809 } \\
\text { NCT04612972 } \\
\text { ChiCTR2000034780 } \\
\text { ChiCTR2000039000 }\end{array}$ & $\begin{array}{l}8 \text { trials in } \\
7 \\
\text { countries }\end{array}$ & Inactivated & 2 & Sinopharm (Wuhan) \\
\hline CoronaVac & $\begin{array}{l}\text { NCT04352608 } \\
\text { NCT04383574 } \\
\text { NCT04551547 } \\
\text { NCT04651790 } \\
\text { NCT04456595 } \\
\text { NCT04508075 } \\
\text { NCT04582344 } \\
\text { NCT04617483 }\end{array}$ & $\begin{array}{l}14 \\
\text { trials in } 7 \\
\text { countries }\end{array}$ & Inactivated & 25 & Sinovac \\
\hline RBD Dimer & $\begin{array}{l}\text { NCT04636333 } \\
\text { NCT04445194 } \\
\text { NCT04466085 } \\
\text { NCT04813562 } \\
\text { NCT04550351 } \\
\end{array}$ & $\begin{array}{l}6 \text { trials in } \\
5 \\
\text { countries }\end{array}$ & $\begin{array}{l}\text { Protein } \\
\text { Subunit }\end{array}$ & 2 & Anhui Zhifei Longcom \\
\hline $\begin{array}{l}\text { SARS -CoV-2 } \\
\text { Vaccine } \\
\text { (Vero Cells) }\end{array}$ & $\begin{array}{l}\text { NCT04758273 } \\
\text { NCT04756323 } \\
\text { NCT04852705 }\end{array}$ & $\begin{array}{l}3 \text { trials in } \\
1 \text { country }\end{array}$ & Inactivated & 1 & Minhai Biotechnology Co. \\
\hline KoviVac & $\begin{array}{l}502 \text { Russian } \\
\text { Federation }\end{array}$ & $\begin{array}{l}2 \text { trials in } \\
1 \text { country }\end{array}$ & Inactivated & 1 & Chumakov Center \\
\hline QazCovid-in & $\begin{array}{l}\text { NCT04530357 } \\
\text { NCT04691908 }\end{array}$ & $\begin{array}{l}3 \text { trials in } \\
1 \text { country }\end{array}$ & Inactivated & 1 & Kazakhstan RIBSP \\
\hline
\end{tabular}


Citation: Shahab MS, Imam SS, Jahangir MA. A Review on the Contemporary Status of Mutating Coronavirus and Comparative Literature Study of Current COVID-19 Vaccines. Int J Pharm Pharmacol 2021; 5: 153. doi: $\underline{10.31531 / 2581-3080.1000153}$

Around 120 vaccine candidates are in development, of which nearby 83 vaccines are in clinical development. Vaccines using different platforms which are currently in Phase 3 are listed in below Table $4[40,43,44]$.

Table 4: List of vaccines currently undergoing Phase 3 studies.

\begin{tabular}{|c|c|c|c|}
\hline Vaccine & NCT number & $\begin{array}{c}\text { Vaccine } \\
\text { type }\end{array}$ & Developers \\
\hline FINLAY-FR-1A & $\begin{array}{l}\text { IFV/COR/05 (Cuba) } \\
\text { IFV/COR/11 } \\
\text { IFV/COR/09 }\end{array}$ & $\begin{array}{l}\text { Protein } \\
\text { Subunit }\end{array}$ & $\begin{array}{l}\text { Instituto Finlay de } \\
\text { Vacunas Cuba }\end{array}$ \\
\hline Recombinant Protein & $\begin{array}{l}\text { NCT04537208 } \\
\text { NCT04762680 } \\
\text { PACTR202011523101903 } \\
\text { (Kenya) }\end{array}$ & $\begin{array}{l}\text { Protein } \\
\text { Subunit }\end{array}$ & Sanofi/GSK \\
\hline CIGB-66 & $\begin{array}{l}\text { RPCEC00000345 (Cuba) } \\
\text { RPCEC00000346 } \\
\text { RPCEC00000359 }\end{array}$ & $\begin{array}{l}\text { Protein } \\
\text { Subunit }\end{array}$ & $\begin{array}{l}\text { Center for Genetic } \\
\text { Engineering and } \\
\text { Biotechnology } \\
\text { (CIGB) }\end{array}$ \\
\hline SCB-2019 & $\begin{array}{l}\text { NCT04405908 } \\
\text { NCT04672395 } \\
\text { PHRR210209-003334 } \\
\text { (Philippines) }\end{array}$ & $\begin{array}{l}\text { Protein } \\
\text { Subunit }\end{array}$ & Clover \\
\hline UB-612 & $\begin{array}{l}\text { NCT04545749 } \\
\text { NCT04683224 } \\
\text { NCT04773067 } \\
\text { NCT04683224 }\end{array}$ & $\begin{array}{l}\text { Protein } \\
\text { Subunit }\end{array}$ & COVAXX \\
\hline FINLAY-FR-2 & $\begin{array}{l}\text { IFV/COR/06(Cuba) } \\
\text { IFV/COR/08 } \\
\text { IFV/COR/09 }\end{array}$ & $\begin{array}{l}\text { Protein } \\
\text { Subunit }\end{array}$ & $\begin{array}{l}\text { Instituto Finlay de } \\
\text { Vacunas Cuba }\end{array}$ \\
\hline EpiVacCorona & $\begin{array}{l}\text { NCT04527575 } \\
\text { NCT04780035 }\end{array}$ & $\begin{array}{l}\text { Protein } \\
\text { Subunit }\end{array}$ & FBRI \\
\hline RBD-Dimer & $\begin{array}{l}\text { NCT04636333 } \\
\text { NCT04445194 } \\
\text { NCT04550351 } \\
\text { NCT04466085 } \\
\text { NCT04646590 } \\
\text { NCT04813562 } \\
\end{array}$ & $\begin{array}{l}\text { Protein } \\
\text { Subunit }\end{array}$ & $\begin{array}{l}\text { Anhui Zhifei } \\
\text { Longcom }\end{array}$ \\
\hline NVX-CoV2373 & $\begin{array}{l}\text { NCT04368988 } \\
\text { NCT04533399 } \\
\text { NCT04583995 } \\
\text { NCT04611802 } \\
\end{array}$ & $\begin{array}{l}\text { Protein } \\
\text { Subunit }\end{array}$ & Novavax \\
\hline Plant-based VLP & $\begin{array}{l}\text { NCT04450004 } \\
\text { NCT04636697 }\end{array}$ & VLP & Medicago \\
\hline INO-4800 & $\begin{array}{l}\text { NCT04336410 } \\
\text { NCT04642638 } \\
\text { NCT04447781 } \\
\text { NCT04642638 } \\
\text { ChiCTR2000040146 (China) }\end{array}$ & DNA & Inovio \\
\hline
\end{tabular}


Citation: Shahab MS, Imam SS, Jahangir MA. A Review on the Contemporary Status of Mutating Coronavirus and Comparative Literature Study of Current COVID-19 Vaccines. Int J Pharm Pharmacol 2021; 5: 153. doi: $\underline{10.31531 / 2581-3080.1000153}$

\begin{tabular}{|c|c|c|c|}
\hline AG0301-COVID19 & $\begin{array}{l}\text { NCT04655625 } \\
\text { NCT04527081 }\end{array}$ & DNA & AnGes \\
\hline ZyCoV-D & $\begin{array}{l}\text { CTRI/2020/07/026352 (India) } \\
\text { CTRI/2021/03/032051 } \\
\text { CTRI/2021/01/030416 }\end{array}$ & DNA & Zydus Cadila \\
\hline mRNA-1273 & $\begin{array}{l}\text { NCT04470427 } \\
\text { NCT04649151 } \\
\text { NCT04405076 } \\
\text { NCT04283461 } \\
\text { NCT04806113 } \\
\text { NCT04805125 } \\
\text { NCT04811664 } \\
\text { NCT04796896 } \\
\text { NCT04811664 } \\
\text { NCT04860297 }\end{array}$ & RNA & Moderna \\
\hline $\mathrm{CVnCoV}$ & $\begin{array}{l}\text { NCT04838847 } \\
\text { NCT04848467 } \\
\text { NCT04449276 } \\
\text { NCT04652102 } \\
\text { NCT04515147 } \\
\text { NCT04860258 } \\
\text { NCT04674189 }\end{array}$ & RNA & Curevac \\
\hline BNT162b1 & $\begin{array}{l}\text { NCT04380701 } \\
\text { NCT04523571 } \\
\text { NCT04368728 } \\
\end{array}$ & RNA & Pfizer/BioNTech \\
\hline mRNA & $\begin{array}{l}\text { ChiCTR2000034112 (China) } \\
\text { ChiCTR2100041855 } \\
\text { ChiCTR2000039212 } \\
\text { NCT04847102 }\end{array}$ & RNA & Walvax \\
\hline BNT162b2 Tozinameran, Comirnaty & $\begin{array}{l}\text { NCT04713553 } \\
\text { NCT04839315 } \\
\text { NCT04368728 } \\
\text { NCT04761822 } \\
\text { NCT04649021 } \\
\text { NCT04816643 } \\
\text { NCT04380701 } \\
\text { NCT04368728 } \\
\text { NCT04588480 } \\
\text { NCT04805125 } \\
\text { NCT04800133 } \\
\text { NCT04754594 } \\
\text { NCT04713553 } \\
\text { ISRCTN69254139 } \\
\text { (South Central - Berkshire } \\
\text { Research Ethics Committee) }\end{array}$ & RNA & Pfizer/BioNTech \\
\hline
\end{tabular}


Citation: Shahab MS, Imam SS, Jahangir MA. A Review on the Contemporary Status of Mutating Coronavirus and Comparative Literature Study of Current COVID-19 Vaccines. Int J Pharm Pharmacol 2021; 5: 153. doi: $\underline{10.31531 / 2581-3080.1000153}$

\begin{tabular}{|c|c|c|c|}
\hline Sputnik V & $\begin{array}{l}\text { NCT04741061 } \\
\text { NCT04642339 } \\
\text { NCT04656613 } \\
\text { NCT04564716 } \\
\text { NCT04741061 } \\
\text { NCT04530396 } \\
\text { NCT04640233 } \\
\text { NCT04686773 } \\
\text { NCT04587219 } \\
\text { NCT04713488 } \\
\text { NCT04436471 } \\
\text { NCT04437875 } \\
\text { NCT04684446 }\end{array}$ & $\begin{array}{l}\text { Non } \\
\text { Replicating } \\
\text { Viral } \\
\text { Vector }\end{array}$ & Gamaleya \\
\hline $\begin{array}{l}\text { Ad26.COV2.S } \\
\text { JNJ-78436735 }\end{array}$ & $\begin{array}{l}\text { NCT04838795 } \\
\text { NCT04505722 } \\
\text { NCT04614948 } \\
\text { NCT04535453 } \\
\text { NCT04436276 } \\
\text { NCT04765384 } \\
\text { NCT04509947 }\end{array}$ & $\begin{array}{l}\text { Non } \\
\text { Replicating } \\
\text { Viral } \\
\text { Vector }\end{array}$ & $\begin{array}{l}\text { Janssen (Johnson \& } \\
\text { Johnson) }\end{array}$ \\
\hline Ad5-nCoV & $\begin{array}{l}\text { NCT04526992 } \\
\text { NCT04540419 } \\
\text { NCT04526990 } \\
\text { NCT04341389 } \\
\text { NCT04566770 } \\
\text { NCT04568811 } \\
\text { NCT04313127 } \\
\end{array}$ & $\begin{array}{l}\text { Non } \\
\text { Replicating } \\
\text { Viral } \\
\text { Vector }\end{array}$ & CanSino \\
\hline AZD1222 & $\begin{array}{l}\text { NCT04536051 } \\
\text { NCT04516746 } \\
\text { NCT04540393 } \\
\text { NCT04400838 } \\
\text { NCT04686773 } \\
\text { NCT04800133 } \\
\text { NCT04885764 } \\
\text { NCT04864561 } \\
\text { CTRI/2020/08/027170(ICMR) } \\
\text { NCT04684446 } \\
\text { NCT04860739 } \\
\text { NCT04444674 } \\
\text { NCT04568031 } \\
\text { NCT04324606 }\end{array}$ & $\begin{array}{l}\text { Non } \\
\text { Replicating } \\
\text { Viral } \\
\text { Vector }\end{array}$ & Oxford/AstraZeneca \\
\hline GRAd-COV2 & $\begin{array}{l}\text { NCT04791423 } \\
\text { NCT04528641 } \\
\text { EUCTR2020-005915-39 } \\
\text { (European Union Clinical } \\
\text { Trials Register) }\end{array}$ & $\begin{array}{l}\text { Non } \\
\text { Replicating } \\
\text { Viral } \\
\text { Vector }\end{array}$ & ReiThera Srl \\
\hline Covishield (ChAdOx1-nCoV-19) & $\begin{array}{l}\text { CTRI/2020/08/027170 } \\
\text { (ICMR) }\end{array}$ & $\begin{array}{l}\text { Non } \\
\text { Replicating } \\
\text { Viral } \\
\text { Vector } \\
\end{array}$ & $\begin{array}{l}\text { Serum Institute of } \\
\text { India }\end{array}$ \\
\hline
\end{tabular}


Citation: Shahab MS, Imam SS, Jahangir MA. A Review on the Contemporary Status of Mutating Coronavirus and Comparative Literature Study of Current COVID-19 Vaccines. Int J Pharm Pharmacol 2021; 5: 153. doi: $\underline{10.31531 / 2581-3080.1000153}$

\begin{tabular}{|c|c|c|c|}
\hline Inactivated (Vero Cells) & $\begin{array}{l}\text { NCT04659239 } \\
\text { NCT04412538 } \\
\text { NCT04470609 } \\
\text { NCT04412538 } \\
\end{array}$ & Inactivated & $\begin{array}{l}\text { Chinese Academy } \\
\text { of Medical Sciences }\end{array}$ \\
\hline SARS-CoV-2 Vaccine (Vero Cells) & $\begin{array}{l}\text { NCT04758273 } \\
\text { NCT04852705 } \\
\text { NCT04756323 } \\
\text { ChiCTR2000038804 } \\
\end{array}$ & Inactivated & $\begin{array}{l}\text { Minhai } \\
\text { Biotechnology Co. }\end{array}$ \\
\hline QazCovid-in, QazVac & $\begin{array}{l}\text { NCT04691908 } \\
\text { NCT04530357 }\end{array}$ & Inactivated & Kazakhstan RIBSP \\
\hline Covaxin & $\begin{array}{l}\text { NCT04641481 } \\
\text { NCT04471519 } \\
\text { CTRI/2020/09/027674 (India) }\end{array}$ & Inactivated & Bharat Biotech \\
\hline BBIBP-CorV & $\begin{array}{l}\text { NCT04510207 } \\
\text { NCT04612972 } \\
\text { NCT04560881, } \\
\text { ChiCTR2000034780 } \\
\text { (Abu Dhabi) } \\
\text { NCT04612972 } \\
\text { NCT04560881 } \\
\end{array}$ & Inactivated & $\begin{array}{l}\text { Sinopharm } \\
\text { (Beijing) }\end{array}$ \\
\hline Inactivated (Vero Cells) & $\begin{array}{l}\text { NCT04510207 } \\
\text { NCT04885764 } \\
\text { NCT04612972 } \\
\text { ChiCTR2000039000 } \\
\text { (Morocco) } \\
\text { ChiCTR2000034780 (Abu } \\
\text { Dhabi) }\end{array}$ & Inactivated & Sinopharm (Wuhan) \\
\hline CoronaVac & $\begin{array}{l}\text { NCT04651790 } \\
\text { NCT04456595 } \\
\text { NCT04800133 } \\
\text { NCT04508075 } \\
\text { NCT04582344 } \\
\text { NCT04617483 } \\
\text { NCT04551547 } \\
\text { NCT04352608 } \\
\text { NCT04383574 } \\
\end{array}$ & Inactivated & Sinovac \\
\hline VLA2001 & $\begin{array}{l}\text { NCT04671017 } \\
\text { NCT04864561 }\end{array}$ & Inactivated & Valneva \\
\hline COVID-19 Inactivated Vaccine & $\begin{array}{l}\text { IRCT20201202049567N1 } \\
\text { IRCT20201202049567N2 } \\
\text { IRCT20201202049567N3 } \\
\text { (Iran) }\end{array}$ & Inactivated & $\begin{array}{l}\text { Shifa Pharmed } \\
\text { Industrial Co. }\end{array}$ \\
\hline
\end{tabular}

Literature Study of Vaccines Approved Under Emergency Use for Coronaviruses (Covid-19)
ChAdOx1 nCoV-19 (AZD1222)

The Oxford university and AstraZeneca developed chimpanzee adenovirus vectored vaccine named ChAdOx1 nCoV-19 (AZD1222) which contains the whole-body structural spike protein of SARS-CoV-2 
[46]. The vaccine also known as Vaxzevria in Europe and Covishield in India developed by joint venture of Serum institute of India, and by SK Bioscience Co. Ltd. South Korea. It is reported with a shelf life of 6 months when stored at $2-8^{\circ} \mathrm{C}$ having 2 shots with duration of 8 12 weeks [47].

According to WHO, the AZD1222 vaccine demonstrated an efficacy of $63.09 \%$ against symptomatic SARS-CoV-2 infection, as specified by the trial participants data in United Kingdom, Brazil and South Africa who received 2 standard doses. Among the participants of age group18 years or above, the vaccine effectiveness was reported to be increased when the duration of doses is longer. In the context of clinical trials of AstraZeneca (AZD1222) no reporting of severe allergic reactions or anaphylaxis was done [48].

The vaccine two dose regimen were $66 \%$ effective against the UK variant B.1.1.7 and 60\% against the Indian B.1.617.2 variant, with only an inadequate decline towards the neutralizing antibody, depicted efficacy against the South African B.1.351 variant. European medicine agency and WHO recommended the use of vaccine in persons aged 18 years and older [4953].

However, according to European medicine agency there is a report of blood clots in the brain, well-known as cerebral venous sinus thrombosis (CVST) occurring together with low levels of platelets (thrombocytopenia) after the vaccination with AstraZeneca vaccines with an occurrence rate of 4 in a million. By the end of March 2021, 79 blood clot cases have been reported in UK itself after the dose of AstraZeneca vaccine. Recently in an article published in European Journal of Medicine concluded that the unusual blood clot with low platelets declared as a uncommon side effects, however the MHRA confirmed in a statement on $7^{\text {th }}$ April 2021 that AstraZeneca continue to outweigh any risk upon vaccination $[54,55]$.

\section{Gamaleya's Sputnik V}

Gamaleya's developed Sputnik V also called as "GamCOVID-Vac" is a vector vaccine combining rAd26 and rAd5 carrier genes for SARS COVID-2 and consist of full-length glycoprotein $\mathrm{S}$. The rAd26-S $0.5 \mathrm{ml} / \mathrm{dose}$ is administered intramuscularly followed by rAd5-S administered at an interval of 21 days. It can be transported globally and is storage at $2-8^{\circ} \mathrm{C}$ [56]. It is the world's first registered vaccine for SARS COVID -2 to be launched in the market. The initial dose is $0.5 \mathrm{ml}$.
The Clinical trials phases 1 and 2 were completed by the end of August 2020 have shown better tolerability and highly immunogenic property in healthy volunteers. The provisional results of the clinical trial NCT04530396 phase 3 Gam-COVID-Vac peer reviewed by the Lancet revealed that the effectiveness of the vaccine is $91.6 \%$ (95\% CI 85.6-95.2) against COVID-19 (from day 21 after first dose, the day of receiving second dose) and is well tolerated in 18 years or elderly participants. Phase 3 clinical trials of Sputnik $\mathrm{V}$ have been conducting in the UAE, India, Venezuela and Belarus [57-59]. The Vaccine showed excellent safety profile. Few adverse effects like Flu symptoms, reactions at the site of injections, headache and chills, nausea were reported however, $94 \%$ of symptoms were mild [57,60]. Gamelya centre Russia carried out a study and revealed that revaccination with SPUTNIK V vaccine is working well on UK variants, but it has shown less effectiveness towards South African Variant [61]. However, according to Russian direct investment fund announced that the 2 dose of vaccine effectively neutralizes the Brazilian variant. Gamelya has also claimed that vaccine is able to combat the Indian variant B.1.1.617 by developing 80 times more antibodies to counter the virus effect $[62,63]$.

A single shot Sputnik Light vaccine, consisting of first component of recombinant human adenovirus serotype number 26 (rAd26) demonstrated 79.4\% efficacy, higher than that of many two-dose vaccines. According to Gamaleya Center it has demonstrated effectiveness against all new strains of coronavirus, with no major adverse effects were reported [64].

\section{Moderna mRNA-1273 SARS-CoV-2 Vaccine}

The Moderna vaccine is a mRNA based encapsulated lipid nanoparticle vaccine which encodes Spike Glycoprotein of SARS-COVID-2 recommended to be used as an immunization programme for 18 year or old individuals against the COVID 19 infection. It is approved under the emergency used listing by US FDA and WHO for immunization program. It needs to be stored between $2-8^{0} \mathrm{C}$ prior to use, the administration is done intramuscular at deltoid site and is required to take 2 doses $(0.5 \mathrm{ml}$ each) within a gap of 4 week [65]

The primary report of phase I clinical trial NCT04283461 demonstrates sufficient immunogenic response subsequently to the first shot. The immune responses were found to rise with time on increasing dose of the vaccine i.e., 25- $\mu \mathrm{g}, 100-\mu \mathrm{g}$ and $250-\mu \mathrm{g}$ [66]. 
In the phase 3 trial (NCT04470427) 28,027 participants of 18 years of age and older were given $100 \mu \mathrm{g}$ of mRNA-1273 vaccine intramuscularly. The vaccine showed $94.1 \%$ efficacy in preventing Covid-19 illness, including severe symptoms [6768]. However, some reports of pain at injection site $(92 \%)$, fatigue and headache were reported which are mild adverse reaction amongst the participants. A report published by European Medicine Agency on in the second week of May 2021 claimed that diarrhoea, immune thrombocytopenia and myocarditis, endocarditis are the new side effects of Moderna vaccine [66,69,70]. Recently, Moderna announced that a single booster of $50 \mu \mathrm{g}$ mRNA-1273 or mRNA-1273.351 has been reported to be more effective against the South African (B.1.351) and Brazilian (P.1) variants and were also found to neutralize the Indian variant B.1.617.1 [71,72].

\section{Comirnaty (BNT162b2)}

The Pfizer-BioNTech developed a nucleoside modified mRNA-based lipid nanoparticle vaccine, authorized by US-FDA under an Emergency Use Authorization (EUA) to be used in individuals of 16 years and older to generate the immune response against the SARSCOVID-2. In May 2021 the lower age limit for vaccine administration was reduced to 12 years of adolescent or older. To be used globally, vaccine BNT162b2 got the emergency used listing by WHO in last week of December 2020 [73]. The recommended dose is 2 shots of $0.3 \mathrm{ml}$ each, administered intramuscularly in deltoid muscle at interval of 21-28 days and need to be stored in freezer between $-25^{\circ} \mathrm{C}$ to $-15^{\circ} \mathrm{C}$ for 2 weeks. Thawed and undiluted vaccine can be refrigerated at $2-8^{\circ} \mathrm{C}$ for 31 days. The clinical trial NCT04368728 phase 3 data published in NEJM reported 95\% protection against SARS-COVID-2 [74,75].

It has displayed an immense report against the olderly individuals with efficacy of $94 \%-95 \%$ in preventing the COVID-19 associated hospitalization aged $\geq 65$ years [76]. According to the study conducted by the Pfizer in March 2021, the BNT162b2 vaccine had been reported with $100 \%$ efficacy in the study of adolescents $\geq 12$ years old. Few side effects such as pain, redness and swelling at site of injection, and other side effects like chill, fever, fatigue were also reported after a day or two of administering the vaccine. However, a study performed in Middle east (Saudi Arabia) indicated Flu like symptoms were more prevalent among individuals below 60 years of age whereas pain at the site of injection was more frequent among the age group 60 years or above. The side effects were majorly in female participants compared to males [76,77]. In another study of Pfizer Comirnaty vaccine performed against B.1.1.7 and B.1.351 variants in Qatar showed effectiveness, of $89.5 \%$ and $75.0 \%$. In a study performed in U.K, the Pfizer vaccine two dose had shown effectiveness of $88 \%$ against Indian variant B.1.617.2 and 93\% against the U.K variant B.1.1.7, also the vaccine has shown effectiveness against the New York B.1.526 and California B.1.429 variants too [50,78-80].

\section{Janssen (Ad26.COV2.S)}

It is a one-shot recombinant vector containing SARS$\mathrm{COV}-2$ virus spike protein sequence and is indicated to be used to develop the immunogenic response in the age group 18 years or older individuals. The vaccine is approved to be used under emergency use by the US FDA and European Medicine agency [81]. The Janssen covid vaccine is reported to be stable for 2 years at $20^{\circ} \mathrm{C}$, and for 3 months if stored between $2-8^{\circ} \mathrm{C}$. In the phase 3 clinical trials study on 43,783 participants received the vaccine; in which $34 \%$ of them were more than 60 years of age and belonged to 8 different countries and 3 continents. The study demonstrated that $41 \%$ individuals have comorbidities associated with higher risk for progression to severe COVID-19. However, the Phase 3 data revealed $85 \%$ effectiveness on protection from hospitalization and mortality after 2 days of vaccination. However, a few mild side effects like pain at injection site, fatigue, headache, nausea etc were reported within 1-2 days after the vaccine administration. Researchers found that Janssen single dose vaccine has shown effectiveness up to $68 \%$ against the P.2 variant of Brazil and to $64 \%$ against B.1.351 variant of South Africa [82-85].

\section{Novavax NVX-CoV2373}

NVX-CoV2373 vaccine comprises of purified recombinant nanoparticle antigens which is obtained from the coronavirus spike protein through the genetic sequencing of SARS covid 19. The preclinical study exhibited that vaccine demonstrated efficiently with human receptors targeted by the virus. The recommended two dose vaccine needs to be administered intramuscularly at 21 days apart, having storage temperature between $2-8^{\circ} \mathrm{C}$. In a report of phase 3 trial participants of 18-84 years were given Novavax 
vaccine dose of $5 \mu \mathrm{g}$ each 3 weeks apart, conferred 89.3 $\%$ protection against Covid-19 prototype and demonstrated the increased efficacy up to $85.6 \%$ against the UK Variant B.1.1.7 [86,87]. According to an article published in NEJM a phase 2a-b trial
NCT04533399 in South Africa, NVX-CoV2373 vaccine administered in adults between 18-84 years of ages, the vaccine demonstrated $100 \%$ protection against the SARS COVID-2 and showed efficacy of $48.6 \%$ against the South African variant B.1.351 [88].

Table 5: Comparative table of approved vaccines for Covid-19, their manufacturer, vaccine type, dose, dosage gap, \%effectiveness, effectiveness against different mutated viruses and storage conditions.

\begin{tabular}{|c|c|c|c|c|c|c|}
\hline $\begin{array}{c}\text { Company name } \\
\text { /Vaccine }\end{array}$ & Vaccine Type & Doses & $\begin{array}{l}\text { Dosage } \\
\text { Gap }\end{array}$ & Effectiveness & $\begin{array}{c}\text { Effectiveness } \\
\text { against } \\
\text { mutated Virus }\end{array}$ & Storage \\
\hline $\begin{array}{l}\text { Oxford Uni-/Astra } \\
\text { Zeneca } \\
\text { AZD12222 }\end{array}$ & Viral Vector & 2 shots & $\begin{array}{l}4-12 \\
\text { weeks } \\
\text { apart }\end{array}$ & $62-90 \%$ & $\begin{array}{l}74.6 \% \text { against } \\
\text { B.1.1.7 variant }\end{array}$ & $2-8^{\circ} \mathrm{C}$ \\
\hline $\begin{array}{l}\text { Moderna } \\
\text { /mRNA-1273 }\end{array}$ & mRNA & 2 shots & $\begin{array}{l}28 \text { days } \\
\text { apart }\end{array}$ & $94.10 \%$ & $\begin{array}{l}\text { B.1.1.7 and } \\
\text { B.1.351 variants }\end{array}$ & $\begin{array}{l}\text { Refrigeration up } \\
\text { to }-20^{\circ} \mathrm{C}\end{array}$ \\
\hline $\begin{array}{l}\text { Pfizer BioNtech/ } \\
\text { BNT162b2 } \\
\text { (COMIRNATY) }\end{array}$ & mRNA & 2 shots & $\begin{array}{l}21 \text { days } \\
\text { apart }\end{array}$ & $95 \%$ & $\begin{array}{l}\text { B.1.1.7, less } \\
\text { effective against } \\
\text { on B.1.351 }\end{array}$ & $\begin{array}{l}\text { Refrigeration up } \\
\text { to }-20^{\circ} \mathrm{C}\end{array}$ \\
\hline $\begin{array}{l}\text { Novavax } \\
\text { NVX-CoV2373 }\end{array}$ & $\begin{array}{l}\text { Protein } \\
\text { adjuvant }\end{array}$ & 2 shots & $\begin{array}{l}3 \text { weeks } \\
\text { apart }\end{array}$ & $89.30 \%$ & $\begin{array}{l}\text { B.1.1.7 variant. } \\
\text { B.1.351 variant }\end{array}$ & $\begin{array}{l}\text { Regular fridge } \\
\text { temperature }\end{array}$ \\
\hline $\begin{array}{l}\text { JANSSEN / } \\
\text { Ad26.COV2.S }\end{array}$ & $\begin{array}{l}\text { Adenovirus- } \\
\text { based }\end{array}$ & 1 shot & ---- & $86 \%$ & $\begin{array}{l}\text { B.1.1.7 variant } \\
\text { B.1.351 }\end{array}$ & $\begin{array}{c}-20^{\circ} \mathrm{C} \text { for two } \\
\text { years }\end{array}$ \\
\hline $\begin{array}{l}\text { Gamelya } \\
\text { /Sputnik V }\end{array}$ & viral vector & 2 shots & $\begin{array}{l}3 \text { weeks } \\
\text { apart }\end{array}$ & $91.60 \%$ & No report & $2-8^{\circ} \mathrm{C}$ \\
\hline $\begin{array}{l}\text { Sinopharm/ } \\
\text { BBIBP-CorV }\end{array}$ & $\begin{array}{l}\text { Inactivated } \\
\text { virus }\end{array}$ & 2 shots & $\begin{array}{l}3-4 \\
\text { weeks }\end{array}$ & $79 \%$ & No report & $2-8^{\circ} \mathrm{C}$ \\
\hline $\begin{array}{l}\text { Sinovac } \\
\text { (Corona Vac) }\end{array}$ & $\begin{array}{l}\text { Inactivated } \\
\text { virus }\end{array}$ & 2 shots & $\begin{array}{l}21 \text { days } \\
\text { apart }\end{array}$ & $50.7 \%-62.3 \%$ & $\begin{array}{l}\text { B.1.351, } \\
\text { B.1.1.7, } \\
\text { B.1.1.28 } \\
\end{array}$ & $2-8^{\circ} \mathrm{C}$ \\
\hline $\begin{array}{l}\text { Bharat Biotech } \\
\text { /Covaxin }\end{array}$ & $\begin{array}{l}\text { Inactivated } \\
\text { virus }\end{array}$ & 2 shots & $\begin{array}{l}4 \text { weeks } \\
\text { apart }\end{array}$ & $81 \%$ & $\begin{array}{l}\text { B.1.351, } \\
\text { B.1.1.7, } \\
\text { B.1.1.28, } \\
\text { B.1.617, }\end{array}$ & $2-8^{\circ} \mathrm{C}$ \\
\hline
\end{tabular}

\section{Sinopharm (BBBIP)}

WHO permitted the emergency use of Sinopharm Inactivated SARS-COV-2 vaccine, for the age group 18 years or above and is considered safe to be administered during pregnancy. There are 2-doses recommended each of $0.5 \mathrm{ml}$ taken at an interval of 3-4 weeks. It is recommended to be stored at $2-8^{\circ} \mathrm{C}$ [89]. The data obtained from the clinical trials performed globally revealed that the vaccine have an efficacy of $79 \%$ against symptomatic COVID 19 however, it has shown better efficacy against the UK variant B.1.1.7 and less effectiveness against the South African B.1.351 variant [90].

\section{CoronaVac}

Sinovac CoronaVac is a 2 dose COVID - 19 vaccine consists of $\beta$-propiolactone inactivated protein 
adjuvanted with alum, administered 14 to 28 days apart to prevent the COVID-19 disease. The Phase 3 clinical trials data of Brazil and Turkey health care workers claimed the vaccine is $100 \%$ effective in preventing COVID 19 infection from becoming severe and fatal cases and $83.7 \%$ to avoid medical attention whereas only $50.65 \%$ efficacy for the diseases caused. According to a study performed in Thailand, $99.49 \%$ of participants developed the antibodies after 4 weeks of injection, and $65.9 \%$ had generated immune responses after 3 weeks. Even though some side effects like pain at the injection site and soreness were majorly reported however, most of the cases were mild [91-93]. The efficacy of the vaccine on new Variant B.1.1.7 originating in U.K shows less resistance as compared to the South African B.1.351 also it has not shown efficacy against the Brazilian variant P.1 and P.2 [94,95].

\section{Covaxin (BBV152)}

India's first home-grown inactive vaccine BBV152 was developed by $\beta$-propiolactone inactivation of Indian strain COVID-19 with the collaboration of Bharat biotech and Indian Council of Medical Research. The vaccination regimen consist of 2 doses should be administered intramuscularly 4 weeks apart and needs to be stored at $2-8^{\circ} \mathrm{C}$. The Phase I and Phase 2 clinical trial data found to have neutralizing effect on COVID19 virus [96]. A randomized Phase 3 trial (CTRI/2020/11/028976) have enrolled around 25800 participants of different age group 18-60 years, the interim result by the Bharat biotech shows 78\% efficacy against the mild to severe symptoms of COVID-19 and $100 \%$ against severe condition an in preventing hospitalization $[91,97]$. The Covaxin is reported to effectively neutralize the U.K variant B.1.17 and Indian Variant B.1.617 of SARS-COVID-2. In January 2021 Government of India granted emergency use authorization to Covaxin, even though the trial is increasing the participants to check efficacy and safety of vaccines [98]. An intranasal vaccine formulation of novel adenovirus named BBV154 against the SARSCOV-2 is under Phase I trial by the Bharat Biotech [99].

Table 5 compares the different vaccines which are being administered currently with their manufacturer, doses required, dosing gap, effectiveness and storage conditions.

\section{Discussion}

A number of laboratories and pharmaceutical companies are involved in formulating the SARS-COV2 vaccine. Currently different vaccines have been developed using different platform and technologies in different countries. These vaccines have gone through a number of clinical trials in their own countries and globally to be used against new Coronavirus strains [100]. The first vaccine launched and authorized to be used in vaccination program was SPUTNIK V which got approval in Russia in August 2020. After that Pfizer/BioNtech vaccine, AstraZeneca/Oxford and Moderna mRNA vaccine and Sinopharm vaccines got the approval under emergency use. However, other leading vaccines of different companies and labs got approval in Russia, China, India etc. These vaccines are to be given to healthy individuals against the SARSCOV-2 and not on the infected individuals. Therefore, demand of vaccines is very high in heavily populated countries for immunization of the masses. Because of the shortage of time of testing and trials the long-term side effects still needs to be uncovered. Therefore, the trials are going on universally to evaluate the efficacy and safety of vaccine. All the leading vaccine developed are injected intramuscularly. Conversely several recent studies depicted the significance of mucosal immune response against the COVID-19 attack. In order to achieve the quick protective response in the mucosa of upper respiratory tract to halt the spreading of SARSCOV-2, researchers and labs are focusing on this strategy. Accordingly, Bharat Biotech India BBV154 intranasal vaccine is under phase I clinical trial, Adcovid intranasal vaccine is under phase 2 trial by Altimmune company of Maryland, and Ad5-based oral SARS-CoV-2 tablets are designed by Vaxart is in phase 1 clinical trial are in progress $[101,102]$. New variants of COVID-19 had been a major challenge on the vaccine effectiveness, as some of the recent variants like B.1.617.2 of India reported to spread 50\% more than the conventional COVID-19 virus. So, to increase the effectiveness of vaccine against these variants there should be development of second and third generation vaccine well supported by clinical trial data. Indeed, the vaccination should be done at mass scale to eradicate the severe COVID-19 symptoms and to minimize the chances of infection.

\section{Conclusion}

Globally more than 16 vaccines are approved under emergency use in their respective countries and few of 
them are approved globally. More than 230 candidates are in clinical and development phases. Out of these 33 candidates are under Phase 3 clinical trials. These multiple vaccine candidates employ different systems of delivering and will prove to be decisive factor against the epidemic fight. If different vaccination options are approved in heavily populated countries like India, it will boost the vaccination in a short period. Also, the use of different vaccine platform will exhibit various types of protection with altered immune responses in 18 years or older patient. However, several trials are performed to decrease the minimum age of vaccination. There are several reports of side effects which appear after 1-2 days of vaccination like pain at the fever, injection site, redness, swelling and other peripheral symptoms which are mild and less in number. Therefore, considering the serious aspects of SARSCOV-2 the mass scale vaccination campaign should be done to elucidate the immunological responses. The developers major challenge is to update the vaccine and raise effectiveness against mutating COVID-19 variants. Finally, special measure must be taken for individuals who are immunologically weak and are not able to develop antibodies even after the $2^{\text {nd }}$ scheduled shot of the vaccine.

\section{Conflict of Interest}

The author declares no conflict of interest.

\section{Funding}

This project did not received funding from any government or private source.

\section{References}

1. Rodriguez-Morales AJ, Bonilla-Aldana DK, Balbin-Ramon GJ et al. History is repeating itself: probable zoonotic spillover as the cause of the 2019 novel coronavirus epidemic; Epidemic Infez Med 2020; 28: 3-5.

2. Gralinski LE, Menachery VD. Return of the Coronavirus: 2019-nCoV. Viruses 2020; 12: 135.

3. Zhu N, Zhang D, Wang W et al. China Novel Coronavirus Investigating and Research Team. 2020. A novel coronavirus from patients with pneumonia in China. N Engl J Med 2019; 382: 727733.
4. Wei X, Li X, Cui J. Evolutionary perspectives on novel coronaviruses identified in pneumonia cases in China. Natl Sci Rev 2020; 7: 239-242.

5. Munster VJ, Koopmans M, Doremalen Nv et al. A novel coronavirus emerging in China-key questions for impact assessment. N Engl J Med 2020; 382: 692-694.

6. Fan Y, Zhao K, Shi ZL, Zhou P. Bat coronaviruses in China. Viruses 2019 March 11:210

7. Lu H. 2020. Drug treatment options for the 2019new coronavirus (2019-nCoV). Biosci Trends 2020; 14: 69-71.

8. Sheahan TP, Sims AC, Leist SR et al. Comparative therapeutic efficacy of remdesivir and combination lopinavir, ritonavir, and interferon beta against MERS-CoV. Nat Commun 2020; 11: 222.

9. Pillaiyar T, Meenakshisundaram S, Manickam M. Recent discovery and development of inhibitors targeting coronaviruses. Drug Discov Today 2020 ;25: 668-688.

10. Lauring AS, Hodcroft EB. Genetic Variants of SARS-CoV-2-What Do They Mean? JAMA 2021; 325: 529-531.

11. https://www.who.int/csr/don/21-december-2020sars-cov2-variant-united-kingdom

12. https://www.who.int/csr/don/31-december-2020sars-cov2-variants/en/

13. Baric RS; Emergence of a Highly Fit SARS-CoV-2 Variant; N Engl J Med 2020; 383: 2684-2686.

14. Arora P, Pöhlmann, S, Hoffmann, M. Mutation D614G increases SARS-CoV-2 transmission. Sig Transduct Target Ther 2021; 6: 101.

15. Mansbach RA, Chakraborty S, KNguyen $\mathrm{K}$ et al. The SARS-CoV-2 Spike variant D614G favors an open conformational state. Science Advances 2021; 7: eabf3671

16. https://cov-lineages.org/global_report.html

17. https://www.cdc.gov/coronavirus/2019ncov/variants/

18. Fontanet A, Autran B, Lina B et al. SARS-CoV-2 variants and ending the COVID-19 pandemic. Lancet 2021; 397: 952-954.

19. Cherian S, Potdar S, Jadhav S et al. Convergent evolution of SARS-CoV-2 spike mutations, L452R, E484Q and P681R, in the second wave of COVID-19 in Maharashtra, India; BioRxiv 2021.

20. Bugembe DL, Phan VT, Ssewanyana I, et al. A SARS-CoV-2 lineage A variant (A.23.1) with 
altered spike has emerged and is dominating the current Uganda epidemic. MedRxiv 2021.

21. https://covid19.who.int/

22. https://www.ecdc.europa.eu/sites/default/files/docu ments/SARS-CoV-2-variant-multiple-spikeprotein-mutations-United-Kingdom.pdf

23. https://www.cdc.gov/coronavirus/2019ncov/more/science-and-research/scientific-briefemerging-variants.html

24. https://covid19.who.int/region/searo/country/in

25. https://www.nature.com/articles/d41586-02101390-4

26. https://www.who.int/en/activities/tracking-SARSCoV-2-variants/

27. Jahangir M.A, Muheem A, Rizvi MF. Coronavirus (COVID-19): History, Current Knowledge and Pipeline Medications. Int J Pharm Pharmacol 2020; 4: 140.

28. https://www.nih.gov/news-events/nih-researchmatters/final-report-confirms-remdesivir-benefitscovid-19

29. Beigel JH, Tomashek KM, Dodd LE, et al. Remdesivir for the Treatment of Covid-19-Final Report. N Engl J Med 2020; 383: 1813-1826.

30. https://www.icmr.gov.in/pdf/covid/techdoc/COVI D19_Management_Algorithm_22042021_v1.pdf

31. https://cdsco.gov.in/opencms/resources/UploadCD SCOWeb/2018/UploadCTApprovals/2-Deoxy-DGlucose\%20(2-DG).pdf

32. Balkrishna A, Singh S, Dev S, et al. Glucose antimetabolite 2-Deoxy-D-Glucose and its derivative as promising candidates for tackling COVID-19: Insights derived from in silico docking and molecular simulations. Authorea 2020.

33. https://pib.gov.in/PressReleasePage.aspx?PRID=1 717007

34. https://www.livemint.com/news/india/2deoxydglu cose-dr-reddy-s-shares-important-information-ondrdo-s-2-dg-covid-drug-details-here-

11621438609404.html

35. Andrew MK, McElhaney JE. Age and frailty in COVID-19 vaccine development. Lancet 2021; 396:1942-1944.

36. Mudenda S. Letter to Editor: Coronavirus Disease (COVID-19): A Global Health Problem. Int J Pharm Pharmacol 2020; 4: 141.

37. https://covid19.who.int/

38. Forni G, Mantovani A. on behalf of the COVID-19 Commission of Accademia Nazionale dei Lincei,
Rome. et al. COVID-19 vaccines: where we stand and challenges ahead. Cell Death Differ 2021; 28: 626-639.

39. Hodgson SH, Mansatta K, Mallett K, et al. What defines an efficacious COVID-19 vaccine? A review of the challenges assessing the clinical efficacy of vaccines against SARS-CoV. Lancet Infect Dis 2021; 21: E26-E35.

40. https://www.fda.gov/emergency-preparednessand-response/coronavirus-disease-2019-covid19/covid-19-vaccines

41. https://www.who.int/news/item/07-05-2021-wholists-additional-covid-19-vaccine-for-emergencyuse-and-issues-interim-policy-recommendations

42. https://www.gavi.org/sites/default/files/covid/cova x/COVAX\%20Supply\%20Forecast.pdf

43. https://clinicaltrials.gov/ct2/show/

44. https://covid19.trackvaccines.org/vaccines/

45. https://www.raps.org/news-and-articles/newsarticles/2020/3/covid-19-vaccine-tracker

46. Rawat K, Kumari P, Saha L. COVID-19 vaccine: A recent update in pipeline vaccines, their design and development strategies. Eur J Pharmacol 2021; 892: 173751.

47. https://extranet.who.int/pqweb/vaccines/covid-19vaccine-chadox1-s-recombinant

48. Knoll MD, Wonodi C. Oxford-Astrazenca COVD19 vaccine efficacy Lancet 2021; 397: 72-74.

49. Emary KRW, Golubchik T, Aley PK, et al. Efficacy of ChAdOx1 nCoV-19 (AZD1222) Vaccine Against SARS-CoV-2 VOC 202012/01 (B.1.1.7): an exploratory analysis of a randomised controlled trial. Lancet 2021; 397: 1351-1362.

50. https://www.clinicaltrialsarena.com/news/phecovid-vaccines-india-variant/

51. https://www.AstraZeneca.com/media-centre/pressreleases/2021/AstraZeneca-covid-19-vaccineauthorised-for-emergency-use-by-the-worldhealth-organization.html

52. https://www.ema.europa.eu/en/medicines/human/E PAR/vaxzevria-previously-covid-19-vaccine-

AstraZeneca

53. WHO Interim recommendations for use of the ChAdOx1-S [recombinant] vaccine against COVID-19 (AstraZeneca COVID-19 vaccine AZD1222, SII Covishield, SK Bioscience); https://www.who.int/publications/i/item/WHO2019-nCoV-vaccines-SAGE_recommendationAZD1222-2021.1 
54. AstraZeneca's COVID-19 vaccine: EMA finds possible link to very rare cases of unusual blood clots with low blood platelets; https://www.ema.europa.eu/en/news/AstraZenecas -covid-19-vaccine-ema-finds-possible-link-veryrare-cases-unusual-blood-clots-low-blood.

55. MHRA issues new advice, concluding a possible link between COVID-19 Vaccine AstraZeneca and extremely rare, unlikely to occur blood clots; https://www.gov.uk/government/news/mhraissues-new-advice-concluding-a-possible-linkbetween-covid-19-vaccine-AstraZeneca-andextremely-rare-unlikely-to-occur-blood-clots

56. Logunov DY, Dolzhikova IV, Shcheblyakov et al. Safety and efficacy of an $\operatorname{rAd} 26$ and rAd5 vectorbased heterologous prime-boost COVID-19 vaccine: an interim analysis of a randomised controlled phase 3 trial in Russia; Lancet 2021; 397 : 671-681.

57. Balakrishnan VS. The arrival of Sputnik V. Lancet Infect Dis 2020; 20: 1128.

58. https://sputnikvaccine.com/about-vaccine/

59. https://clinicaltrials.gov/ct2/show/NCT04530396

60. Jones I, Roy P. Sputnik V COVID-19 vaccine candidate appears safe and effective. Lancet 2021; 397: 642-643.

61. https://www.reuters.com/article/us-healthcoronavirus-sputnik-mutations-idUSKBN2AR0E7

62. https://tass.com/world/1283807

63. https://www.pharmiweb.com/press-release/202105-26/a-study-in-argentina-confirms-sputnik-vhighly-effective-against-manaus-variant-ofcoronavirus

64. https://sputnikvaccine.com/newsroom/pressrelease s/single-dose-vaccine-sputnik-light-authorized-foruse-in-russia/

65. https://www.modernatx.com/covid19vaccineeua/providers/dosing-administration

66. https://www.modernatx.com/covid19vaccineeua/providers/clinical-trial-data

67. https://clinicaltrials.gov/ct2/show/NCT04283461

68. Baden RL, Sahly HM, Essink B, et al; Efficacy and Safety of the mRNA-1273 SARS-CoV-2 Vaccine; N Engl J Med 2021; 384: 403-416.

69. https://www.ema.europa.eu/en/documents/covid19-vaccine-safety-update/covid-19-vaccine-safetyupdate-covid-19-vaccine-moderna-11-may2021_en.pdf

70. Hernández AF, Calina D, Poulas K, et al. Safety of COVID-19 vaccines administered in the EU:
Should we be concerned? Toxicol Rep 2021; 8: 871-879.

71. Deva Priya SA, Kavitha S, Venugopal P, et al. Can mRNA Vaccines Turn the Tables During the COVID-19 Pandemic? Current Status and Challenges. Clin Drug Investig 2021: 1-11.

72. https://investors.modernatx.com/newsreleases/news-release-details/moderna-announcespositive-initial-booster-data-against-sars-cov

73. https://www.fda.gov/emergency-preparednessand-response/coronavirus-disease-2019-covid19/pfizer-biontech-covid-19-vaccine\#additional

74. https://www.cdc.gov/vaccines/covid-19/info-byproduct/pfizer/index.html

75. Polack PF, Thomas SJ, Kitchin N, et al. Safety and Efficacy of the BNT162b2 mRNA Covid-19 Vaccine. N Engl J Med 2020; 383: 2603-2615.

76. https://www.cdc.gov/mmwr/volumes/70/wr/mm70 18e1.htm?s_cid=mm7018e1_w

77. El-Shitany NA, Harakeh S, Badr-Eldin SM et al. Minor to Moderate Side Effects of PfizerBioNTech COVID-19 Vaccine Among Saudi Residents: A Retrospective Cross-Sectional Study. Int J Gen Med 2021; 14: 1389-1401.

78. Iacobucci G. Covid-19: Single vaccine dose is $33 \%$ effective against variant from India, data show; BMJ 2021; 373: n1346

79. Abu-Raddad LJ, Chemaitelly H. Effectiveness of the BNT162b2 Covid-19 Vaccine against the B.1.1.7 and B.1.351 Variants; N Engl J Med 2021: NEJMc2104974.

80. Liu Y, Liu J, Xia H, et. al. BNT162b2-Elicited Neutralization against New SARS-CoV-2 Spike Variants; N Engl J Med 2021: NEJMc2106083

81. .https://www.who.int/groups/strategic-advisorygroup-of-experts-on-immunization/covid-19materials.

82. https://www.jnj.com/johnson-johnson-covid-19vaccine-authorized-by-u-s-fda-for-emergencyusefirst-single-shot-vaccine-in-fight-againstglobal-pandemic

83. https://www.cdc.gov/vaccines/covid-19/info-byproduct/janssen/downloads/janssen-storagehandling-summary.pdf

84. Sadoff J, Gray G, Vandebosch A, et. al. Safety and Efficacy of Single-Dose Ad26.COV2.S Vaccine against Covid-19. N Engl J Med 2021; NEJMoa2101544.

85. https://www.beckershospitalreview.com/pharmacy /j-j-vaccine-effective-against-virus-variants-studyshows.html 
86. Heath TP, Galiza EP, Baxter DN et al. Efficacy of the NVX-CoV2373 Covid-19 Vaccine Against the B.1.1.7 Variant. MedRxiv 2021.

87. https://ir.novavax.com/news-releases/newsrelease-details/novavax-covid-19-vaccinedemonstrates-893-efficacy-uk-phase-3

88. https://ir.novavax.com/news-releases/newsrelease-details/new-england-journal-medicinepublishes-phase-2b-clinical-trial

89. https://www.who.int/news-room/featurestories/detail/the-sinopharm-covid-19-vaccinewhat-you-need-to-know

90. Huang B, Dai L, Wang H, et al. Neutralization of SARS-CoV-2 VOC 501Y.V2 by human antisera elicited by both inactivated BBIBP-CorV and recombinant dimeric RBD ZF2001 vaccines; BioRixv 2021.

91. Kyriakidis, NC, Lopez-Cortes A, Gonzalez EV, et al. SARS-CoV-2 vaccines strategies: a comprehensive review of phase 3 candidates. npj Vaccines 2021; 6, 28.

92. Zhang PY, Zeng G, Pan H, et al. Safety, tolerability, and immunogenicity of an inactivated SARS-CoV-2 vaccine in healthy adults aged $18-59$ years: a randomised, double-blind, placebocontrolled, phase 1/2 clinical trial. Lancet Infect Dis 2021; 21: 181-192.

93. https://www.precisionvaccinations.com/vaccines/c oronavac-covid-19-vaccine

94. Wang GL, Wang ZY, Duan LJ, et al. Susceptibility of Circulating SARS-CoV-2 Variants to
Neutralization; N Engl J Med 2021; NEJMc2103022.

95. De Souza WM, Amorim MR, Sesti-Costa R, et al. Levels of SARS-CoV-2 Lineage P.1 Neutralization by Antibodies Elicited after Natural Infection and Vaccination. SSRN 2021 (Ahead of Print).

96. Ella R, Reddy S, Jogdand H, et al. Safety and immunogenicity of an inactivated SARS-CoV-2 vaccine, BBV152: interim results from a doubleblind, randomised, multicentre, phase 2 trial, and 3month follow-up of a double-blind, randomised phase 1 trial. Lancet Infect Dis 2021: S14733099(21)00070-0.

97. https://www.bharatbiotech.com/covaxin.html

98. Yadav PD, Sapkal GN, Abraham P, et al. Neutralization of variant under investigation B.1.617 with sera of BBV152 vaccinees. Clin Infect Dis 2021: ciab411.

99. https://www.bharatbiotech.com/intranasalvaccine.html

100. Ghalib RM. Letter to Editor: Vitamin D Fighting Against Novel Coronavirus (SARS-CoV-2). Int J Pharm Pharmacol 2020; 4: 147.

101. Isho B, Abe KT, Zuo M, et al. Persistence of serum and saliva antibody responses to SARS-CoV-2 spike antigens in COVID-19 patients. Sci Immunol 2020; 5: eabe5511.

102. Hassan AO, Kafai NM, Dmitriev IP, et al. A singledose intranasal ChAd vaccine protects upper and lower respiratory tracts against SARS-CoV2. Cell 2020; 183: 169-184.

This manuscript was peer-reviewed

Mode of Review: Single-blinded

Academic Editor: Dr. Steward Mudenda

Copyright: (02021 Shahab MS, et al. This article is distributed under the terms of the Creative Commons Attribution 4.0 International License (http://creativecommons.org/licenses/by/4.0/), which permits unrestricted use, distribution, and reproduction in any medium, provided you give appropriate credit to the original author(s) and the source, provide a link to the Creative Commons license, and indicate if changes were made. 